\title{
Correction to: Preclinical and Clinical Trials of Indian Medicinal Plants in Disease Control
}

Md. Harun Al Rashid, Anindita Kundu, Vivekananda Mandal, Phurpa Wangchuk, and Subhash C. Mandal

\section{Correction to:}

\section{S. Sen, R. Chakraborty (eds.), Herbal Medicine in India,} https://doi.org/10.1007/978-981-13-7248-3_9

The original version of Chapter 9 was inadvertently published with incorrect author name "Harun $\mathrm{Al}$ Rashid" instead of "Md. Harun Al Rashid". The chapter has been updated. 